\title{
Upgrading of Biomass-Derived Feedstocks to Liquid Transportation Fuel Precursors by Aldol Condensation
}

\author{
Chengjun Jiang \\ Department of Chemical \& Biological Engineering, Zhejiang University of Science and Technology, Hangzhou, China \\ Email: jcj312@zust.edu.cn
}

How to cite this paper: Jiang, C.J. (2020) Upgrading of Biomass-Derived Feedstocks to Liquid Transportation Fuel Precursors by Aldol Condensation. Open Access Library Journal, 7: e6185.

https://doi.org/10.4236/oalib.1106185

Received: February 24, 2020

Accepted: March 17, 2020

Published: March 20, 2020

Copyright $\odot 2020$ by author(s) and Open Access Library Inc.

This work is licensed under the Creative Commons Attribution International License (CC BY 4.0).

http://creativecommons.org/licenses/by/4.0/

\section{(c) (i) Open Access}

\begin{abstract}
The upgrading of biomass-derived feedstocks to liquid transportation fuels is complex because of the chemical differences between biomass-derived chemicals and conventional fuels. Aldol condensation may play an important role in converting biomass-derive components to fuels because it allows smaller species to be converted to larger species that are more similar to conventional fuels. This review covers recent progress in aldol condensation of biomass-derived 5-hydroxymethylfurfural, acetone, methyl ketones, acetoin, levulinic acid, furfural, cyclopentanone and levulinic acid. The corresponding catalytic mechanisms and future research directions in these areas are also discussed.
\end{abstract}

\section{Subject Areas \\ Chemical Engineering \& Technology}

\section{Keywords}

Biomass, Fuels, Aldol Condensation, Review

\section{Introduction}

World use of petroleum and other liquid fuels is projected to grow from 90 million barrels per day (b/d) in 2012 to 100 million b/d in 2020 and to 121 million $\mathrm{b} / \mathrm{d}$ in 2040 [1]. Most of the growth in liquid fuels consumption is in the transportation and industrial sectors. The environmental impacts associated with greenhouse gas emissions (GHG) emissions resulting from combustion of fossil fuels have motivated the search of new technologies for a sustainable production of transportation fuels [2]. Utilization of renewable resources for the preparation 
of transportation fuels has potential advantages in the reduction of our dependence on fossil resources [3]. Biomass is a renewable resource that can also reduce GHG by capturing $\mathrm{CO}_{2}$ during photosynthesis [4]. There are several methods to convert biomass into liquid transportation fuels including fast pyrolysis [5] [6], liquefaction [7] [8] and Fischer Tropsch synthesis [9]. These strategies convert biomass to upgradeable platforms such as bio-oil or syngas [10]. Another important route involves aldol condensation of biomass-derived feedstocks to upgrade small oxygenates to larger ones that are more similar in molecular size to conventional fuels. These biomass-derived feedstocks include methyl ketones [11], n-Butanal [12], 5-Hydroxymethylfurfural [13] [14] [15] and other ketones and aldehydes. Aldol condensation has a number of advantages compared with fast pyrolysis, liquefaction, and Fischer-Tropsch synthesis. For example, extreme temperature and pressures are not required, unlike Fischer-Tropsch synthesis or liquefaction. In addition, this process has much higher selectivity compared with fast pyrolysis, which produces a wide variety of products.

Herein, we review the most advanced progress in the use of aldol condensation as a method for preparation of liquid transportation fuels. In particular, we focus on that catalysts achieve both a high conversion and a high selectivity. Because hydrodeoxygenation has been intensively summarized and reviewed by many research groups [16] [17], we do not discuss this field in this review.

\section{Mechanism of Aldol Condensation}

Although aldol condensation is an important and well-known organic reactions because of its ability to form new C-C bonds, its mechanism has never been fully established [18]. Aldol condensation includes reactions producing $\beta$-hydroxy aldehydes or $\beta$-hydroxy ketones by self condensation or mixed condensation of aldehydes and ketones as well as reactions leading to $\alpha, \beta$-unsaturated aldehydes or $\alpha, \beta$-unsaturated ketones formed by dehydration of intermediate $\beta$-aldols or $\beta$-ketals.

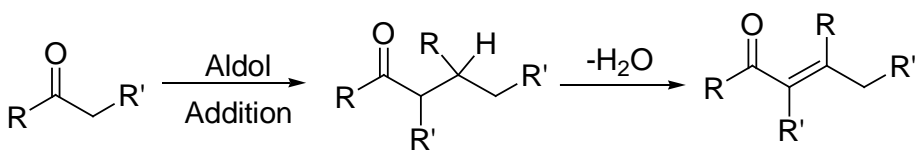

$\mathrm{R}=\mathrm{H}$, aldehydes

self condensation

$\mathrm{R}=\mathrm{H}, \alpha, \beta$-unsaturated aldehydes

Aldol condensation of aldehydes can be catalyzed by acid, base or acid-base bifunctional catalysts [19] [20]. In aldol condensation catalyzed by base (Scheme 1 ), an enolate is formed by the abstraction of the $\alpha$-hydrogen of the carbonyl compound with the help of a base. The enolate then attacks the second carbonyl molecule. This leads to formation of another ionic species which extracts the proton from the protonated base (HB). This finally leads to the formation of the aldol (or if a ketone was present as the starting material, a ketol). Next the aldol 


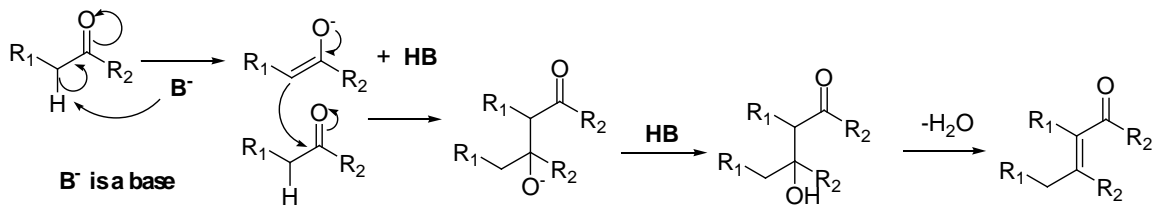

Scheme 1. Aldol condensation catalyzed by base.

(or ketol) undergoes spontaneous dehydration due to base catalyzed dehydration to yield the $\alpha, \beta$-unsaturated aldehyde or $\alpha, \beta$-unsaturated ketone.

Which step is the rate-limiting step of the aldol condensation was discussed [18], rate-limiting step in the base-catalyzed aldol condensation of benzaldehydes with acetophenones is the final loss of hydroxide and formation of the $\mathrm{C}=\mathrm{C}$ bond. When an acid is used to catalyze aldol condensation (Scheme 2), the acid acts as a proton donor and activates the carbonyl oxygen into a protonated form. The protonated carbonyl then reacts with the conjugate base of the acid to produce the enol, followed by conjugation of the enol with another protonated carbonyl compound to produce the aldol (or ketol). Completing the reaction, the aldol (or ketol) undergoes spontaneous dehydration due to acid catalyzed dehydration to yield the $\alpha, \beta$-unsaturated aldehyde or $\alpha, \beta$-unsaturated ketone.

Aldol condensation is generally carried out in the presence of base catalysts. Including basic compounds (alkali metals or alkaline earth oxides), hydrogen oxidation, bicarbonate, carbonate, carboxylate, organic amine compounds, Anion exchange resin and so on. The solid base catalysts that are active in organic liquid phases or in the vapor phase. Few studies have been reported for aldol condensation using solid base catalysts in water, because leaching of catalyst components into the water phase and poor hydrothermal stability pose significant challenges. In actual industrial applications, the alkaline catalysts used in the aldol condensation reaction can be weak bases (such as sodium carbonate, sodium bicarbonate, sodium acetate), or strong bases (such as sodium hydroxide, calcium hydroxide, sodium hydroxide, sodium alcohol, etc.). Weak bases are usually used for condensation between active aldehydes. Products are generally $\beta$-hydroxyl compounds. Strong bases are usually used for condensation of ketone with large steric hindrance. Acid catalysts are often used in aldol condensation reactions [19] [20]. Commonly used acid catalysts include $\left(\mathrm{VO}_{2} \mathrm{P}_{2} \mathrm{O}_{7}, \mathrm{VOHPO}_{4}\right)$, niobate and MFI zeolite. Acid-base catalyst also has an acidic alkaline active site, such as two oxide oxides or hydrotalcite which is suitable for gas phase aldol condensation and liquid phase. The application of acid-base catalyst in aldol condensation reaction is more and more important.

\section{Aldol Condensation of Biomass-Derived Carbonyl Molecule}

\subsection{Aldol Condensation between 5-Hydroxymethylfurfural and Acetone}

5-hydroxymethylfurfural (HMF) is a suitable platform chemical for the production of useful chemicals and fuels [21]. Recently, efforts have been devoted to the 


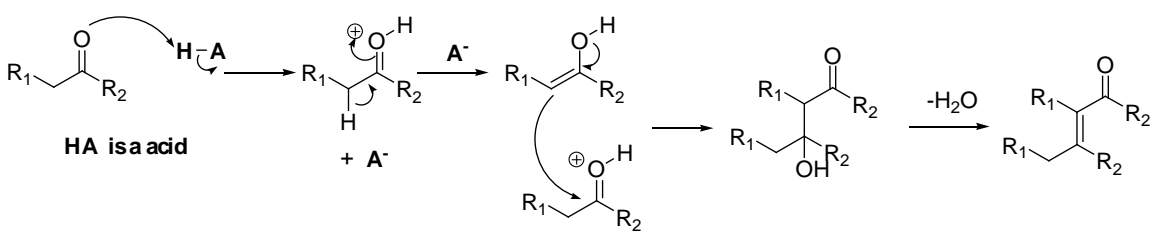

Scheme 2 . Aldol condensation catalyzed by acid.

conversion of biomass into 5-hydroxymethylfurfural (HMF) (Table 1), and excellent efficiencies have been achieved for both fructose and glucose. The HMF yields were as high as $96 \%$ and $81 \%$ for fructose and glucose, respectively [22]. Typically, aldol condensation furfural and ketones is catalyzed by solid base catalysts [23] [24].
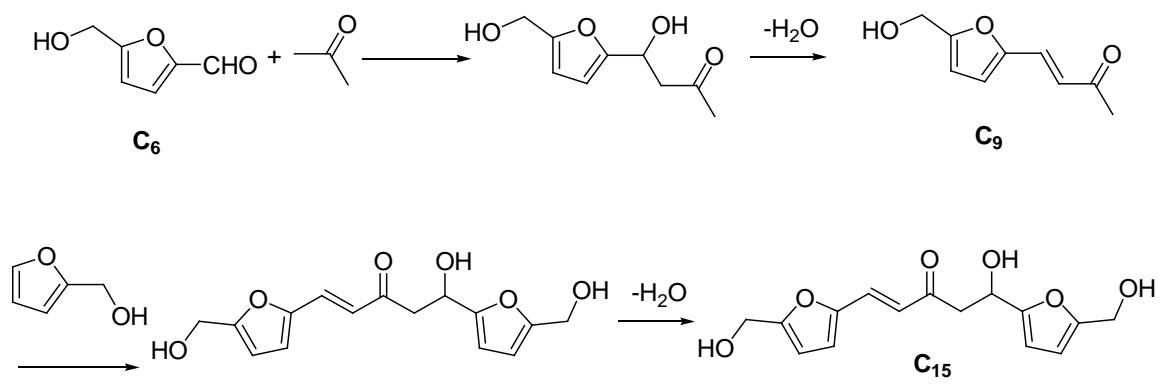

Once produced, HMF can be combined with other aldehydes and ketones to produce longer carbon chains that can eventually be converted to hydrocarbon fuels, A variety of solid base catalysts have been used for aldol condensation between HMF and acetone. Zirconium carbonate $\mathrm{Zr}\left(\mathrm{CO}_{3}\right)_{\mathrm{x}}$ was used as a water tolerant solid base catalyst, producing $92 \%$ C 9 aldol products at nearly $100 \% \mathrm{HMF}$ conversion. The activity of $\mathrm{Zr}\left(\mathrm{CO}_{3}\right)_{\mathrm{x}}$ was maintained for five consecutive cycles. Aldol products were further hydrodeoxygenated with a bifunctional $\mathrm{Pd} /$ Zeolite catalyst in ethanol, producing n-nonane and 1-ethoxynonane with $40 \%$ and $56 \%$ selectivity, respectively. Basic $\mathrm{MgO}-\mathrm{ZrO}_{2}$ [25], $\mathrm{MgAl}$ and $\mathrm{MgZr}$ mixed oxides have also been studied for aqueous-phase 5-hydroxymethylfurfural-acetone aldol condensation. The highest $\mathrm{C} 15$ selectivity is obtained in stoichiometric conditions (2:1). MgZr catalyst shows better than MgAl to aldol condensation products, especially for the formation of the second adduct $\left(\mathrm{C}_{15}\right)$. The best results were obtained working with $0.5 \mathrm{~g}$ of $\mathrm{MgZr}$, at $323 \mathrm{~K}$. The highest $\mathrm{C}_{15}$ yield was reached with 5-HMF excess (2:1) (16.1\%), whereas the whole yield is maximized at equimolar conditions (37\%). $\mathrm{CO}_{2}$-Catalysed aldol condensation of 5-hydroxy-methylfurfural and acetone to a jet fuel precursor was reported by Roland Lee et al. [26], $\mathrm{CO}_{2}$-Catalysed aldol condensation of HMF with acetone gives a $>95 \%$ yield, with the mono-aldol condensate as the only detected product. $\mathrm{Cu} / \mathrm{MgAl}_{2} \mathrm{O}_{4}$ as bifunctional catalyst for aldol condensation of 5-Hydroxymethylfurfural and acetone [27], magnesium aluminate exhibits superior activity compared to zinc and cobalt-based aluminates, reaching full conversion and up to $81 \%$ yield of the $1: 1$ aldol product. The high activity can be 
Table 1. Heterogeneous catalysts for aldol Condensation between 5-Hydroxymethylfurfural and acetone.

\begin{tabular}{|c|c|c|c|c|c|}
\hline Entry & Catalyst & Methods & Conversion (\%) & Selectivity (\%) & Reference \\
\hline 1 & $\mathrm{Zr}\left(\mathrm{CO}_{3}\right)_{\mathrm{x}}$ & aqueous solution & 100 & C9:92 & 13 \\
\hline 2 & $\mathrm{MgO}-\mathrm{ZrO}_{2}$ & aqueous solution & 93.3 & $\begin{array}{c}\text { aldol product: } 55.9 \\
\text { C9:50.4, C15:49.6 }\end{array}$ & 25 \\
\hline 3 & $\mathrm{MgAl}$ & aqueous solution & 27.2 & C9:25.6, C15:17.1 & 14 \\
\hline 4 & $\mathrm{MgZr}$ & aqueous solution & 53.4 & C9:43.4, C15:49.6 & 14 \\
\hline 5 & $\mathrm{CO}_{2}$ & $200^{\circ} \mathrm{C}, \mathrm{CO}_{2} \mathrm{MPa}$ & $>95 \%$ & C9 > 95\% & 26 \\
\hline 6 & $\mathrm{Cu} / \mathrm{MgAl}_{2} \mathrm{O}_{4}$ & Acetone as solvent & 100 & $\mathrm{C} 9: 78, \mathrm{C} 15: 7$ & 27 \\
\hline 7 & FAU-type zeolite nanosheets & Solvent free & 91.74 & C9: close to $100 \%$ & 28 \\
\hline
\end{tabular}

correlated to a higher concentration of basic surface sites on magnesium aluminate. Applying continuous regeneration, the catalysts can be recycled without loss of activity. The $\mathrm{Cu} / \mathrm{MgAl}_{2} \mathrm{O}_{4}$ catalyst was used in the hydrogenation of condensation products and showed high selectivity for C-O bond cleavage of primary alcohols, delivering 3-hydroxybutyl-5-methylfuran as the main product. Amine-grafted hierarchical basic FAU-type zeolite nanosheets for the aldol condensation of 5-hydroxymethylfurfural (5-HMF) and acetone (Ac) has been studied [28]. The superior catalytic performance achieved due to the synergistic effect of hierarchical structures, featuring basic active sites together with surface modification. Theoretical study on the reaction mechanisms of the aldol-condensation of 5-hydroxymethylfurfural with acetone catalyzed by $\mathrm{MgO}$ and $\mathrm{MgO}^{+}$were reported [29], The reaction mechanism involves the crucial reaction steps of $\mathrm{H}$-shift and $\mathrm{C}-\mathrm{C}$ bond formation, while the rate-determining step is concerned to the $\mathrm{H}$-shift. The Lewis acidity of the cationic $\mathrm{MgO}^{+}$makes it exhibit better catalytic performance than the neutral $\mathrm{MgO}$. Water, as a bridge in the $\mathrm{H}$-shift, interacts with both the neutral $\mathrm{MgO}$ and the cationic $\mathrm{MgO}^{+}$moieties, leading to the Brønsted basicity, and then promoting the catalytic performance both of the neutral $\mathrm{MgO}$ and the cationic $\mathrm{MgO}^{+}$. Both the Lewis acidity and Brønsted basicity of active sites can enhance the catalytic performance in the aldol-condensation of HMF with acetone.

\subsection{Condensation of Biomass-Derived Aliphatic Ketones}

Ketones can be produced from biomass-derived sugars, suggesting that they could be possible starting compounds for synthesis of liquid fuels. For example, it was reported that acetone/butanol/ethanol (ABE) mixtures produced by Clostridial fermentation of sugars can be catalytically converted to aliphatic ketones [30] Potential starting ketone such as 2-butanone which can be produced by acid-catalyzed dehydration of fermentative 2,3-butanediol [31] 2,3-butanediol can be produced with concentrations up to $152 \mathrm{~g} / \mathrm{L}$ [32] by various bacterial strains belonging mainly in the genera Klebsiella, Serratia, Bacillus, Paenibacillus and Enterobacter. A mixture of $\mathrm{n}$-alkyl methyl ketones and their derivatives obtained 
from bio-mass via base catalyzed aldol condensation and Michael addition, further hydrodeoxygenation of these products, possible to produce jet fuel. Condensation of aliphatic ketones is a very complex reaction and numerous products are possible via competitive self-condensation and cross-condensation between the same or different ketones that are formed in the reaction.

Typical reactions of self-condensation of ketones in the presence of $\mathrm{MgAlO}$ or niobic acid catalysts as shown in Scheme 3.

In the presence of base $(\mathrm{MgAlO})$, the selective of $\mathrm{C}_{3 n}$ isomers (3) is higher than $\mathrm{C}_{2 \mathrm{n}}$ isomers and $\mathrm{C}_{3 \mathrm{n}}$ isomers (4) [33].

Mg-Al Hydrotalcite Catalysts was also used to aldol condensation of benzaldehyde and acetone, hydrotalcites should transformed into basic solids by activation, the activity went through a maximum after calcination at $723 \mathrm{~K}$, followed by rehydration by water vapor at room temperature. It was suggests that aldolisation is catalysed by $\mathrm{OH}^{-}$[34].

An aldol yield higher than 85 mol\% was obtained after optimum activation.. Highly selective trimerization of methyl ketones catalyzied by $\mathrm{MgAlO}$ to produce bio-lubricants were reported [35] (Scheme 4).

Calcined niobic acid $\left(\mathrm{Nb}_{2} \mathrm{O}_{5}\right)$ contains a considerable amount of water, nevertheless it shows a high acidity on the surface corresponding to the acidity of $70 \%$ sulfuric acid [36]. $\mathrm{Nb}_{2} \mathrm{O}_{5}$ exhibits not only a high activity and selectivity but also a remarkably good stability as a catalyst for the reactions in which water molecules participate or are liberated [37]. However, in the presence of acid $\left(\mathrm{Nb}_{2} \mathrm{O}_{5}\right)$ catalysts, hindered internal ketones condense to form $\mathrm{C}_{2 n}$ isomers (2), ketones containing methyl functionality at one end form $\mathrm{C}_{3 n}$ isomers (4), mainly aromatic compounds. Acid catalysts $\mathrm{Ta}_{2} \mathrm{O}_{5} / \mathrm{SBA}-15$ was also used to self-condensation of biomass-derived methyl ketones, which promote dehydration leading to the production of aromatic products.

\subsection{Aldol Condensation of Acetoin with Lignocellulose Derived Aldehydes}

Acetoin, a novel C4 platform molecule derived from new ABE (acetoin-butanolethanol) type fermentation via metabolic engineering [38], can be used as a bio-based building block for the production of liquid hydrocarbon fuels [39], as shown in Scheme 5.

The condensation reaction between two acetoin molecules is slow because of steric hindrance and because the electron donating properties of the attached

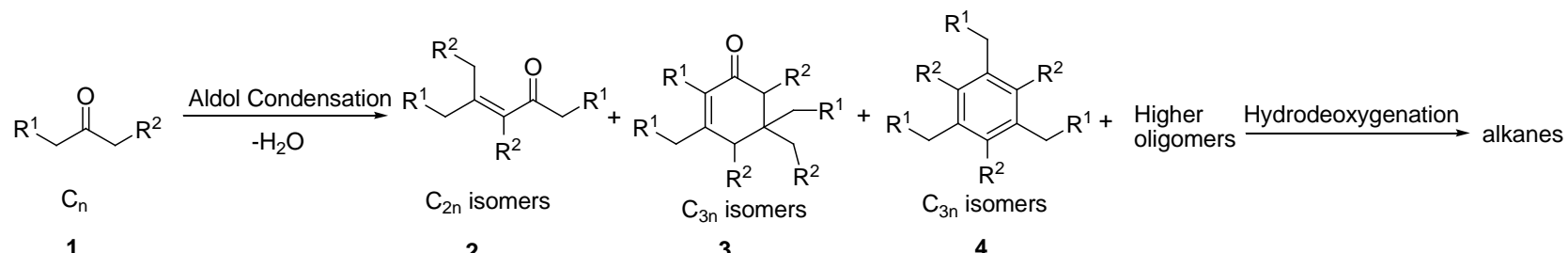

Scheme 3. Self-condensation of ketones in the presence of solid acid/base catalysts. 


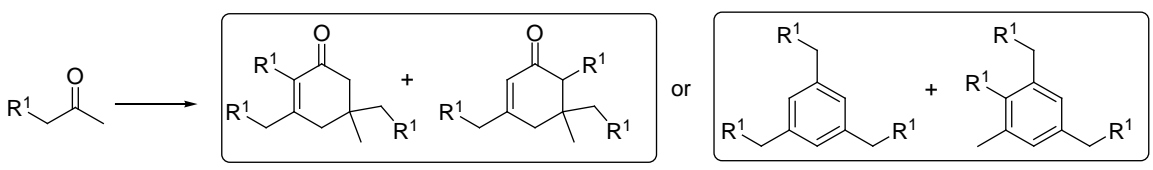

Scheme 4. Aldol self-condensation of n-alkyl methyl ketones.

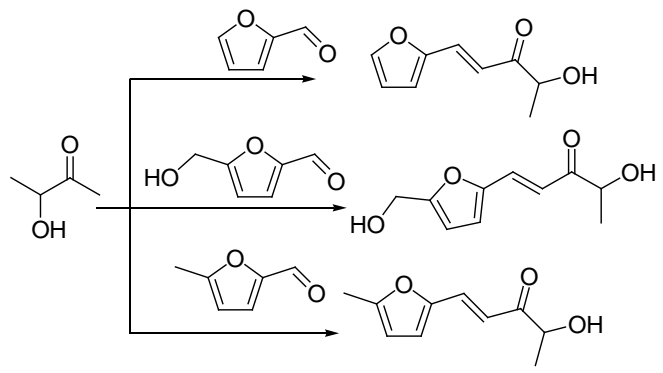

Scheme 5. Synthesis of diesel or jet range alkanes using acetoin as a bio-based synthon.

hydroxyl groups prevent the formation of the reactive enolate intermediate. However, acetoin easily reacts with lignocellulose derived aldehydes, including 5-hydroxymethylfurfural or 5-methylfurfural. Solid base catalysts were tested for furfural and acetoin, except for $\mathrm{MgO}-\mathrm{ZrO}_{2}$ exhibiting moderate catalytic activity, other solid base were unsatisfactory. Organocatalysts such as L-proline, tryptophan, and 1,8-diazabicycloundec-7-ene were failed to catalyze this aldol reaction.

\subsection{Aldol Condensation of Furfural with Acetone}

Furfural and acetone are readily available chemicals, which can be produced by the hydrolysis of biomass [40].

Liquid phase aldol condensation of furfural and acetone catalyzed by solid base catalysts ( $\mathrm{Mg}$ - $\mathrm{Al}$ hydrotalcites and $\mathrm{Mg}$ - $\mathrm{Al}$ mixed oxides) has been investigated. The best results were achieved with calcined catalyst sample having $\mathrm{Mg} / \mathrm{Al}$ molar ratio equal to 3 at $100^{\circ} \mathrm{C}$ ( $>95 \%$ furfural conversion and $>90 \%$ selectivity to the 4-(2-furyl)-3-buten-2-one and 1,5-di-2-furyl-2,4-pentadien-1-one). The catalytic performance of the prepared $\mathrm{TiO}_{2}$ sample in aldol condensation of furfural with acetone was evaluated and compared with those for Mg-Al hydrotalcites [41] and BEA zeolite [42] (Scheme 6). It showed that uncalcined $\mathrm{TiO}_{2}$ possesses good activity which could be competitive with that reported for other inorganic solids. Aldol condensation between aldehyde and ketone over $\mathrm{TiO}_{2}$ proceeded with the participation of basic rather than acidic sites [43]. Potassium-containing BEA zeolites were prepared by ion-exchange from $\mathrm{NH}_{4}$-BEA with potassium nitrate aqueous solution or ion-exchange combined with impregnation were used as basic catalysts for aldol condensation of furfural and acetone [44]. The ion-exchanged K-BEA catalysts exhibited low activity in the aldol condensation because of a weak strength of intrinsic basic sites. In contrast, the samples prepared by ion exchange combined with impregnation possessed strong basic sites, plausibly $\mathrm{K}_{2} \mathrm{O}$ clusters, and demonstrated appreciable activity 


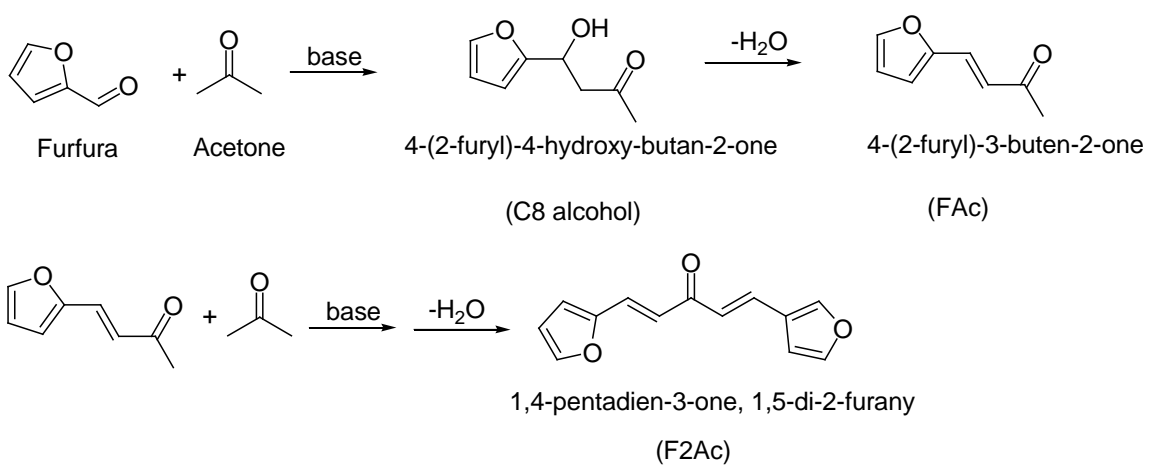

Scheme 6. Aldol condensation of furfural with acetone.

in the aldol condensation. Solid base catalysts $\mathrm{MgO}-\mathrm{ZrO}_{2}, \mathrm{NaY}$ and nitrogensubstituted $\mathrm{NaY}$ (Nit-NaY) were studied for aldol condensation reactions, The aldol condensation of furfurals with acetone produces two different products, the monomer and the dimer. The monomer is formed from reaction of furfurals with acetone. The dimer is formed from reaction of the monomer with furfurals. $\mathrm{MgO}-\mathrm{ZrO}_{2}$ had a higher selectivity towards dimer formation. In contrast, Nit-NaY was more selective towards the monomer product due to the cage size in the FAU structure, indicating that Nit-NaY is a shape selective base catalyst.

\subsection{Aldol Condensation of Biomass-Derived Levulinic Acid and Furfural}

Levulinic acid (LA) is one of the most promising platform chemicals derived from biomass. The efficient production of LA (about $80 \%$ yield) from biomass has been achieved on a large scale through the Biofine Process [45]. The aldol condensation of furfural with levulinic acid in the aqueous phase was investigated over a series of solid catalysts [46] (Scheme 7), including oxides ( $\mathrm{MgO}$, $\mathrm{ZnO}, \mathrm{TiO}_{2}, \mathrm{ZrO}_{2}, \mathrm{MgO}-\mathrm{Al}_{2} \mathrm{O}_{3}, \mathrm{CeO}_{2}, \mathrm{Nb}_{2} \mathrm{O}_{5}, \mathrm{SnO}_{2}$, and $\mathrm{WO}_{3}$ ) and acidic zeolites (HY, H $\beta$, HZSM-5, H-MOR, and SAPO-34).

$\mathrm{MgO}$ is an effective basic catalyst for synthesis of $\mathrm{C} 4$ and $\mathrm{C} 8$ chemicals from ethanol [47]. The aldol reaction of levulinic acid and furfural on $\mathrm{MgO}$ is supposed to be difficult. Own to both types of $\alpha-\mathrm{H}$ in the levulinic molecule could be activated by a base, which resulted in a mixture of two $\mathrm{C} 10$ oxygenates with poor selectivity. Two isomeric condensation products, $\beta$ - and $\delta$-furfurylidenelevulinic acids ( $\beta$ - and $\delta$-FDLA) were produced via two fundamentally different mechanisms. The formation of $\delta$-FDLA on MgO follows a typical base-catalyzed mechanism, while the formation of $\beta$-FDLA on $\mathrm{ZnO}$ is via an acid-catalyzed mechanism. LA could then be used as a cheap and easily available biomass feedstock for further transformations by aldol condensation.

\subsection{Aldol Condensation of Furfural with Cyclopentanone}

The furfural conversion about $98 \%$ and cyclopentanone yield of $92.1 \mathrm{~mol} \%$ were achieved using only $1 \mathrm{wt} \%$ concentration of $5 \% \mathrm{Pd}-10 \% \mathrm{Cu} / \mathrm{C}$ catalyst and a reaction time of $1 \mathrm{~h}$ [48]. The product of Aldol condensation of furfural with 


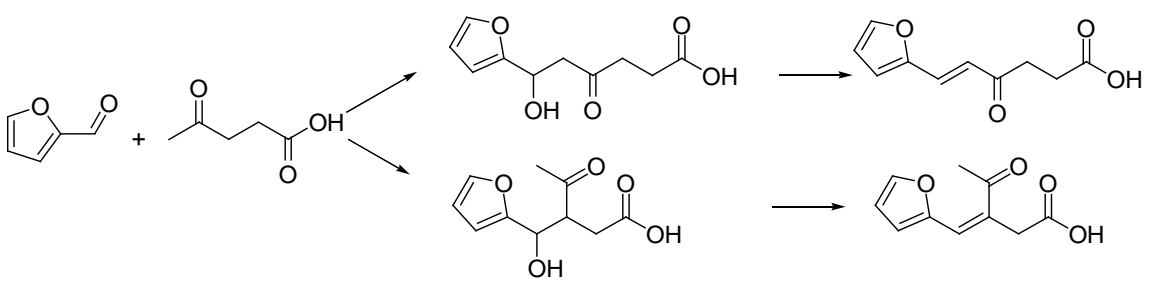

Scheme 7. Aldol condensation of levulinic acid and furfural.

cyclopentanone yields a cyclic ether that could be considered as biomass-derived diesel blending agent for transportation fuels [49] (Scheme 8).

The aldol condensation of furfural with cyclopentanone is achieved with a low concentration of base and a molar ratio of the reactants of $2: 1$. This reaction is highly selective. After $40-80 \mathrm{~min}$ of reaction at a temperature of $40^{\circ} \mathrm{C}-100^{\circ} \mathrm{C}$, more than 95 mol\% yield of 2,5-bis(2-furylmethylidene) cyclopentan-1-one was obtained [50]. Subsequent hydrogenation/hydro-deoxygenation steps yield a dialkylcyclopentane that could be used as a diesel or jet fuel.

\subsection{Self-Condensation of Levulinic Acid}

Most of previously studied reactions are focused on the reactivity of the carboxyl group of the levulinic acid, transformation of levulinic acid into g-valerolactone with industrial interest [51]. The base-catalyzed condensation of levulinic acid (LA) under mild conditions was proposed as a new approach for the upgrading of this molecule by using mixed oxides as catalysts [52] (Scheme 9).

Aldol condensation of levulinicacid would yield a mixture of $\mathrm{C} 10-\mathrm{C} 15$ adducts. These adducts could have high value as fuel additives or surfactants, and hydrodeoxygenation of these compounds would result in a good-quality liquid fuel without needing further purification steps. $\mathrm{MgAl}, \mathrm{MgZr}$ and $\mathrm{MgZr} / \mathrm{HSAG}$ were used as catalyts. The best results were obtained with $\mathrm{MgZr}$, for which a 33\% conversion of levulinic acid was observed after $24 \mathrm{~h}$ with almost $83 \%$ selectivity for the formation of condensation products.

$\mathrm{Nb}_{2} \mathrm{O}_{5}$ catalyst with excellent activity and stability in the aldol condensation of biomass-derived carbonyl molecules (Scheme 10). It is found that in the aldol condensation of furfural with 4-heptanone, $\mathrm{Nb}_{2} \mathrm{O}_{5}$ has obviously superior activity, which is not only better than that of other common solid acid catalysts $\left(\mathrm{ZrO}_{2}\right.$ and $\mathrm{Al}_{2} \mathrm{O}_{3}$ ), more importantly, but also better than that of solid base catalysts ( $\mathrm{MgO}, \mathrm{CaO}$, and magnesium-aluminum hydrotalcite) [53]. Optimization of the process conditions for minimizing the aldol condensation recently reported by many research groups [54] [55].

\section{Conclusions}

While some interesting information has been forwarded by aldol condensation of biomass-derived feedstocks studies, several gaps remain in this very important research area. These gaps can be divided into economic and technology gaps. From an economical viewpoint, economic feasibility plays a crucial role in the 
2<smiles>CC1CC[C+](C=O)C1=O</smiles>

Scheme 8. Aldol condensation of furfural with cyclopentanone.<smiles>COC(=O)CCC(C)=O</smiles>

Scheme 9. Self-condensation of levulinic acid.

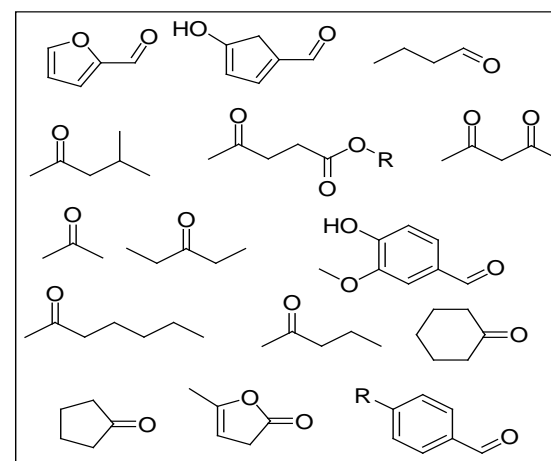

Biomass-derived carbonyl molecules

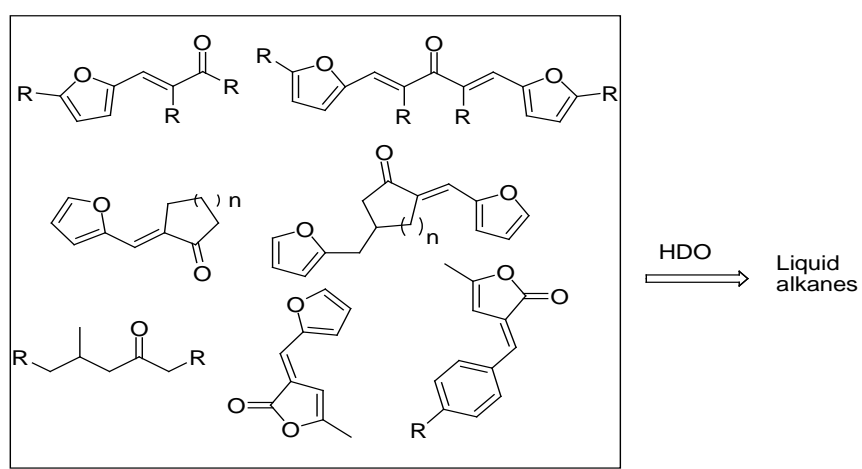

Fuel precursors

Scheme 10. Aldol condensation of biomass-derived carbonyl molecules.

field, and fuels are a low-value commodity produced on a very large scale. Therefore, development of economical processes for fuel production requires a large investment in both money and time. The cost of producing transportation fuels from biomass is controlled primarily by the costs associated with the processing of biomass to produce the fuel, making it imperative to develop new processes for the conversion of biomass to liquid fuels, which involves a limited number of processing steps. However, no literature is available to offer detailed information on the energy recovery and economic analysis of the heterogeneous catalytic conversion of biomass-derived feedstocks in the aqueous phase. Given that water has a higher heat capacity and results in worse corrosion than organic solvents, the energy consumption of water and equipment maintenance may lead to higher costs. Hence, a reliable study of economic feasibility should be done to design an efficient process.

From a technical viewpoint, extensive research on biomass-derived feedstocks, catalyst systems as well as reactor technology is well studied in this area. The fundamental chemistry of most of these reactions is not well understood, and it is likely that further scientific understanding will lead us to improved processes. 
To obtain high-quality fuels, multiple transformation routes are required to increase the carbon-chain length and to decrease the oxygen content. A continuous or one-pot process can be designed to meet this requirement. We believe that efficient processes for the sustainable production of biofuels will be continuous in the future.

\section{Acknowledgements}

We gratefully acknowledge support from Zhejiang public welfare technology research plan (LGJ20B060001).

\section{Conflicts of Interest}

The authors declare no conflicts of interest regarding the publication of this paper.

\section{References}

[1] Conti, J., Holtberg, P., Diefenderfer, J., LaRose, A., Turnure, J.T. and Westfall, L. International Energy Outlook 2016 with Projections to 2040. 1-5.

https://www.osti.gov/biblio/1296780

[2] Hronec, M., Fulajtárova, K., Liptaj, T., Prónayová, N. and Soták, T. (2015) Bio-Derived Fuel Additives from Furfural and Cyclopentanone. Fuel Processing Technology, 138, 564-569. https://doi.org/10.1016/j.fuproc.2015.06.036

[3] Huber, G.W., Iborra, S. and Corma, A. (2006) Synthesis of Transportation Fuels from Biomass: Chemistry, Catalysts, and Engineering. Chemical Reviews, 106, 4044-4098. https://doi.org/10.1021/cr068360d

[4] Patel, M. and Kumar, A. (2016) Production of Renewable Diesel through the Hydroprocessing of Lignocellulosic Biomass-Derived Bio-Oil: A Review. Renewable and Sustainable Energy Reviews, 58, 1293-1307.

https://doi.org/10.1016/j.rser.2015.12.146

[5] Carlson, T.R., Vispute, T.P. and Green, G.H. (2008) Gasoline by Catalytic Fast Pyrolysis of Solid Biomass Derived Compounds. ChemSusChem, 1, 397-400. https://doi.org/10.1002/cssc.200800018

[6] Bridgwater, A.V. (2012) Review of Fast Pyrolysis of Biomass and Product Upgrading. Biomass and Bioenergy, 38, 68-94. https://doi.org/10.1016/j.biombioe.2011.01.048

[7] López Barreiro, D., Ronsse, F. and Brilman, W. (2013) Hydrothermal Liquefaction (HTL) of Microalgae for Biofuel Production: State of the Art Review and Future Prospects. Biomass and Bioenergy, 53, 113-127. https://doi.org/10.1016/j.biombioe.2012.12.029

[8] Kumar, S., Lange, J.P., Van Rossum, G. and Kersten, S.R.A. (2015) Liquefaction of Lignocellulose in Fluid Catalytic Cracker Feed: A Process Concept Study. ChemSusChem, 8, 4086-4094. https://doi.org/10.1002/cssc.201500457

[9] Snehesh Shivananda Ail, S.D. (2016) Biomass to Liquid Transportation Fuel via Fischer Tropsch Synthesis-Technology Review and Current Scenario. Renewable and Sustainable Energy Reviews, 58, 267-286.

https://doi.org/10.1016/j.rser.2015.12.143

[10] Lan, W., Chen, G., Zhu, X., Wang, X. and Xu, B. (2015) Progress in Techniques of Biomass Conversion into Syngas. Journal of the Energy Institute, 88, 151-156. 
https://doi.org/10.1016/j.joei.2014.05.003

[11] Sacia, E.R., Balakrishnan, M., Deaner, M.H., Goulas, K.A., Toste, F.D. and Bell, A.T. (2015) Highly Selective Condensation of Biomass-Derived Methyl Ketones as a Source of Aviation Fuel. ChemSusChem, 8, 1726-1736. https://doi.org/10.1002/cssc.201500002

[12] Shylesh, S., Hanna, D., Gomes, J., Canlas, C.G., Head-Gordon, M. and Bell, A.T. (2015) The Role of Hydroxyl Group Acidity on the Activity of Silica-Supported Secondary Amines for the Self-Condensation of n-Butanal. ChemSusChem, 8, 466-472. https://doi.org/10.1002/cssc.201402443

[13] Bohre, A., Saha, B. and Abu-Omar, M.M. (2015) Catalytic Upgrading of 5-Hydroxymethylfurfural to Drop-In Biofuels by Solid Base and Bifunctional Metal-Acid Catalysts. ChemSusChem, 8, 4022-4029. https://doi.org/10.1002/cssc.201501136

[14] Cueto, J., Faba, L. and Eva Díaz, S.O. (2017) Performance of Basic Mixed Oxides for Aqueous-Phase 5-Hydroxymethylfurfural-Acetone Aldol Condensation. Applied Catalysis B: Environmental, 201, 221-231. https://doi.org/10.1016/j.apcatb.2016.08.013

[15] Wang, L. and Chen, E.Y.X. (2015) Recyclable Supported Carbene Catalysts for High-Yielding Self-Condensation of Furaldehydes into C10 and C12 Furoins. ACS Catalysis, 5, 6907-6917. https://doi.org/10.1021/acscatal.5b01410

[16] Choudhary, T.V. and Phillips, C.B. (2011) Renewable Fuels via Catalytic Hydrodeoxygenation. Applied Catalysis A: General, 397, 1-12.

https://doi.org/10.1016/j.apcata.2011.02.025

[17] Dea, S. and Basudeb Saha, R.L. (2015) Hydrodeoxygenation Processes: Advances on Catalytic Transformations of Biomass-Derived Platform Chemicals into Hydrocarbon Fuels. Bioresource Technology, 178, 108-118. https://doi.org/10.1016/j.biortech.2014.09.065

[18] Charles, L. (2016) Perrin and Kuei-Lin Chang. The Complete Mechanism of an Aldol Condensation. The Journal of Organic Chemistry, 81, 5631-5635. https://doi.org/10.1021/acs.joc.6b00959

[19] Hernandez, W.Y., Alic, F., Verberckmoes, A. and Tuning, P.V.D.V. (2017) The Acidic-Basic Properties by $\mathrm{Zn}$-Substitution in $\mathrm{Mg}$-Al Hydrotalcites as Optimal Catalysts for the Aldol Condensation Reaction. Journal of Materials Science, 52, 628-642. https://doi.org/10.1007/s10853-016-0360-3

[20] Pham, T.N., Zhang, L., Shi, D.C., Komarneni, M.R., Ruiz, M.P., Resasco, D.E. and Fine-Tuning, J.F. (2016) The Acid-Base Properties of Boron-Doped Magnesium Oxide Catalyst for the Selective Aldol Condensation. ChemCatChem, 8, 3611-3620. https://doi.org/10.1002/cctc.201600953

[21] Howard, J., Rackemann, D.W., Bartley, J.P., Samori, C., et al. (2018) Conversion of Sugar Cane Molasses to 5-Hydroxymethylfurfural Using Molasses and Bagasse-Derived Catalysts. ACS Sustainable Chemistry \& Engineering, 6, 4531-4538. https://doi.org/10.1021/acssuschemeng.7b02746

[22] Yong, G., Zhang, Y. and Ying, J.Y. (2008) Efficient Catalytic System for the Selective Production of 5-Hydroxymethylfurfural from Glucose and Fructose. Angewandte Chemie-International Edition, 47, 9345-9348.

https://doi.org/10.1002/anie.200803207

[23] Chheda, J.N. and Dumesic, J.A. (2007) An Overview of Dehydration, Aldol-Condensation and Hydrogenation Processes for Production of Liquid Alkanes from Biomass-Derived Carbohydrates. Catalysis Today, 123, 59-70.

https://doi.org/10.1016/j.cattod.2006.12.006 
[24] Li, S., Chen, F., Li, N., et al. (2017) Synthesis of Renewable Triketones, Diketones, and Jet-Fuel Range Cycloalkanes with 5-Hydroxymethylfurfural and Ketones. ChemSusChem, 10, 711-719.

[25] Shen, W., Tompsett, G.A., Hammond, K.D., Xing, R., Dogan, F., Grey, C.P., Conner, W.C., Auerbach, S.M. and Huber, G.W. (2011) Liquid Phase Aldol Condensation Reactions with $\mathrm{MgO}-\mathrm{ZrO}_{2}$ and Shape-Selective Nitrogen-Substituted NaY. Applied Catalysis A: General, 392, 57-68. https://doi.org/10.1016/j.apcata.2010.10.023

[26] Lee, R., et al. (2016) $\mathrm{CO}_{2}$-Catalysed Aldol Condensation of 5-Hydroxy-Methylfurfural and Acetone to a Jet Fuel Precursor. Green Chemistry, 18, 5118-5121. https://doi.org/10.1039/C6GC01697A

[27] Pupovac, K. and Palkovits, R. (2013) $\mathrm{Cu} / \mathrm{MgAl}_{2} \mathrm{O}_{4}$ as Bifunctional Catalyst for Aldol Condensation of 5-Hydroxymethylfurfural and Selective Transfer Hydrogenation. ChemSusChem, 6, 2103-2110. https://doi.org/10.1002/cssc.201300414

[28] Suttipat, T.Y. (2017) Aldol Condensation of Biomass-Derived Platform Molecules over Amine-Grafted Hierarchical FAU-Type Zeolite Nanosheets (Zeolean) Featuring Basic Sites. Chemical Communications, 53, 123185-12188. https://doi.org/10.1039/C7CC06375I

[29] Chen, S., Yang, H.Q., et al. (2015) Theoretical Study on the Reaction Mechanisms of the Aldol-Condensation of 5-Hydroxymethylfurfural with Acetone Catalyzed by $\mathrm{MgO}$ and $\mathrm{MgO}+$. Catalysis Today, 245, 100-107. https://doi.org/10.1016/j.cattod.2014.05.004

[30] Anbarasan, P., Baer, Z.C., Sreekumar, S., et al. (2012) Integration of Chemical Catalysis with Extractive Fermentation to Produce Fuels. Nature, 491, 235-239. https://doi.org/10.1038/nature11594

[31] Multer, A., McGraw, N., Hohn, K. and Vadlani, P. (2013) Production of Methyl Ethyl Ketone from Biomass Using a Hybrid Biochemical/Catalytic Approach. Industrial \& Engineering Chemistry Research, 52, 56-60. https://doi.org/10.1021/ie3007598

[32] Koutinas, A.A., Yepez, B., Kopsahelis, N., Freire, D.M.G., de Castro, A.M., Papanikolaou, S. and Kookos, I.K. (2016) Techno-Economic Evaluation of a Complete Bioprocess for 2,3-Butanediol Production from Renewable Resources. Bioresource Technology, 204, 55-64. https://doi.org/10.1016/j.biortech.2015.12.005

[33] Balakrishnan, M., et al. (2015) Novel Pathways for Fuels and Lubricants from Biomass optimized Using Life-Cycle Greenhouse Gas Assessment. Proceedings of the National Academy of Sciences of the United States of America, 112, 7645-7649. https://doi.org/10.1073/pnas.1508274112

[34] Gravelle, K.K., et al. (1998) Activation of Mg-Al Hydrotalcite Catalysts for Aldol Condensation Reactions Kottapalli. Journal of Catalysis, 173, 115-121. https://doi.org/10.1006/jcat.1997.1878

[35] Balakrishnan, M., Arab, G.E., Kunbargi, O.B., Gokhale, A.A., Grippo, A.M., Toste, F.D. and Bell, A.T. (2016) Production of Renewable Lubricants via Self-Condensation of Methyl Ketones. Green Chemistry, 18, 1-5. https://doi.org/10.1039/C6GC00579A

[36] Nakajima, K., Baba, Y., Noma, R., et al. (2011) $\mathrm{Nb}_{2} \mathrm{O}_{5} 3 \mathrm{nH}_{2} \mathrm{O}$ as a Heterogeneous Catalyst with Water-Tolerant Lewis Acid Sites. Journal of the American Chemical Society, 133, 4224-4227. https://doi.org/10.1021/ja110482r

[37] Lebarbier, V., Houalla, M. and Onfroy, T. (2012) New Insights into the Development of Bronsted Acidity of Niobic Acid. Catalysis Today, 192, 123-129. https://doi.org/10.1016/j.cattod.2012.02.061

[38] Zhang, B., Li, X.-L., Fu, J., et al. (2016) Production of Acetoin through Simultaneous 
Utilization of Glucose, Xylose, and Arabinose by Engineered Bacillus subtilis. PLoS ONE, 11, e0159298. https://doi.org/10.1371/journal.pone.0159298

[39] Zhu, C.J., Shen, T., Liu, D., et al. (2016) Production of Liquid Hydrocarbon Fuels with Acetoin and Platform Molecules Derived from Lignocellulose. Green Chemistry, 18, 2165-2174. https://doi.org/10.1039/C5GC02414E

[40] Li, X.D., Jia, P., et al. (2016) Furfural: A Promising Platform Compound for Sustainable Production of C4 and C5 Chemicals. ACS Catalysis, 6, 7621-7640. https://doi.org/10.1021/acscatal.6b01838

[41] Kikhtyanin, O., Hora, L., et al. (2015) Unprecedented Selectivities in Aldol Condensation over Mg-Al Hydrotalcite in a Fixed Bed Reactor Setup. Catalysis Communications, 58, 89-92. https://doi.org/10.1016/j.catcom.2014.09.002

[42] Thanh, D.N., Kikhtyanin, O., Ramos, R., et al. (2016) Nanosized $\mathrm{TiO}_{2}$-A Promising Catalyst for the Aldol Condensation of Furfural with Acetone in Biomass Upgrading. Catalysis Today, 277, 97-107. https://doi.org/10.1016/j.cattod.2015.11.027

[43] Hora, L., et al. (2014) Aldol Condensation of Furfural and Acetone over Mg-Al Layered Double Hydroxides and Mixed Oxides. Catalysis Today, 223, 138-147. https://doi.org/10.1016/j.cattod.2013.09.022

[44] Kikhtyanin, O., Bulánek, R., Frolich, K., et al. (2016) Aldol Condensation of Furfural with Acetone over Ion-Exchanged and Impregnated Potassium BEA Zeolites. Journal of Molecular Catalysis A: Chemical, 424, 358-368. https://doi.org/10.1016/j.molcata.2016.09.014

[45] Pileidis, F.D. and Titirici, M.M. (2016) Levulinic Acid Biorefineries: New Challenges for Efficient Utilization of Biomass. ChemSusChem, 9, 562-582. https://doi.org/10.1002/cssc.201501405

[46] Liang, G.F., Wang, A.Q., Zhao, X.C., et al. (2016) Selective Aldol Condensation of Biomass-Derived Levulinic Acid and Furfural in Aqueous-Phase over $\mathrm{MgO}$ and ZnO. Green Chemistry, 18, 3430-3438. https://doi.org/10.1039/C6GC00118A

[47] Zhang, L., Pham, T.N., Faria, J., Santhanaraj, D., Sooknoi, T., Tan, Q., Zhao, Z. and Resasco, D.E. (2016) Synthesis of C4 and C8 Chemicals from Ethanol on MgO-Incorporated Faujasite Catalysts with Balanced Confinement Effects and Basicity. ChemSusChem, 9, 736-748. https://doi.org/10.1002/cssc.201501518

[48] Hronec, M., Fulajtárová, K., Vávra, I., Soták, T., Dobročka, E. and Mičušík, M. (2016) Carbon Supported Pd-Cu Catalysts for Highly Selective Rearrangement of Furfural to Cyclopentanone. Applied Catalysis B: Environmental, 181, 210-219. https://doi.org/10.1016/j.apcatb.2015.07.046

[49] Hronec, M., et al. (2016) Nickel Catalysed Hydrogenation of Aldol Condensation Product of Furfural with Cyclopentanone to C15 Cyclic Ethers. ChemistrySelect, 2, 331-336. https://doi.org/10.1002/slct.201500001

[50] Hronec, M., Fulajtárova, K., Liptaj, T., Štolcová, M., Prónayová, N. and Soták, T. (2014) Cyclopentanone: A Raw Material for Production of C15 and C17 Fuel Precursors. Biomass and Bioenergy, 63, 291-299. https://doi.org/10.1016/j.biombioe.2014.02.025

[51] Matzker, G. and Burtoloso, A.C.B. (2015) Conversion of Levulinic Acid into c-Valerolactone Using $\mathrm{Fe}_{3}(\mathrm{CO})_{12}$ : Mimicking a Biorefinery Setting by Exploiting Crude Liquors from Biomass acid Hydrolysis. Chemical Communications, 51, 14199-14202. https://doi.org/10.1039/C5CC02993G

[52] Faba, L., Díaz, E. and Ordóñez, S. (2016) Base-Catalyzed Condensation of Levulinic Acid: A New Biorefinery Upgrading Approach. ChemCatChem, 8, 1490-1494. https://doi.org/10.1002/cctc.201600064 
[53] Jing, Y., Xin, Y., Guo, Y., Liu, X. and Wang, Y. (2019) Highly Efficient $\mathrm{Nb}_{2} \mathrm{O}_{5}$ Catalyst for Aldol Condensation of Biomass-Derived Carbonyl Molecules to Fuel Precursors. Chinese Journal of Catalysis, 40, 1168-1177. https://doi.org/10.1016/S1872-2067(19)63371-1

[54] Cueto, J., Faba, L., Díaz, E. and Ordóñez, S. (2020) Optimization of the Process Conditions for Minimizing the Deactivation in the Furfural-Cyclopentanone Aldol Condensation in a Continuous Reactor. Applied Catalysis B: Environmental, 263, Article ID: 118341. https://doi.org/10.1016/j.apcatb.2019.118341

[55] Ngo, D.T., Tan, Q., Wang, B. and Resasco, D.E. (2019) Aldol Condensation of Cyclopentanone on Hydrophobized MgO. Promotional Role of Water and Changes in Rate-Limiting Step upon Organosilane Functionalization. ACS Catalysis, 9, 28312841. https://doi.org/10.1021/acscatal.8b05103 